\title{
Current Use of Thiazide Diuretics and Prevention of Femur Fractures
}

\author{
Ron M. C. Herings, ${ }^{1 *}$ Bruno H. C. Stricker, ${ }^{2}$ \\ Anthonius de Boer, ${ }^{1}$ Albert Bakker, ${ }^{1}$ Ferd Sturmans, ${ }^{3}$ and Andy Stergachis ${ }^{4}$ \\ I DEPARTMENT OF PHARMACOEPIDEMIOLOGY AND PHARMACOTHERAPY, UTRECHT INSTITUTE FOR PHARMACEUTICAL \\ SCIENCES (UIPS), UTRECHT UNIVERSITY, UTRECHT, THE NETHERLANDS, ${ }^{2}$ DEPARTMENT OF INTERNAL MEDICINE II, \\ PHARMACOEPIDEMIOLOGY UNIT, ERASMUS UNIVERSITY ROTTERDAM, ROTTERDAM, THE NETHERLANDS, \\ ${ }^{3}$ DEPARTMENT OF EPIDEMIOLOGY, FACULTY OF MEDICINE, LIMBURG UNIVERSITY, LIMBURG, THE NETHERLANDS, \\ AND ${ }^{4}$ DEPARTMENTS OF PHARMACY AND EPIDEMIOLOGY, UNIVERSITY OF WASHINGTON, SEATTLE, WASHINGTON
}

\begin{abstract}
A case control study of a defined population from The Netherlands was performed to evaluate the risk of femur fractures associated with the use of thiazide diuretics. Included were 386 patients hospitalized for femur fractures between 1986 and 1990 who were residents and 45 years of age and older. Per case, one age-, sex-, pharmacy-, and general practitioner-matched control was chosen from the general population. Drug use was ascertained from computerized pharmacy records. The adjusted odds ratio of current use of thiazide diuretics was 0.5 (95\% confidence interval, 0.3-0.9).The protective effect of thiazide diuretics was greatest for use of 1 year or longer at relatively high doses of thiazides (odds ratio, $0.3 ; 95 \%$ confidence interval, $0.1-0.9$ ). We also found that patients who discontinued thiazide use longer than 2 months were not protected against femur fractures. These results support the hypothesis that use of thiazide diuretics protects against femur fractures. I CLIN EPIDEMIOL 49;1:115-119, 1996.
\end{abstract}

KEY WORDS. Thiazide diuretics, femur fractures, case control study, pharmacotherapy, pharmacoepidemiology

\section{INTRODUCTION}

Femur fractures are a major public health problem among the elderly. In The Netherlands, the number of hospitalizations for femur fractures has increased two- to threefold since the mid-1970s [1]. By 1990 The Netherlands experienced approximately 16,000 admissions for femur fractures, estimated to exceed direct costs of 235 million US\$ annually [2].

The vast majority of the hip fractures among elderly are typically osteoporotic fractures of the proximal femur [3]. With the aging of society, the treatment and prevention of bone loss is therefore of the utmost importance. However, available drug therapies are either limited to women or have been associated with untoward effects [4]. During the past decades, experimental studies showed that use of thiazide diuretics slows bone loss, most probably through an increase in the renal reabsorption of calcium [5,6]. This slowing of bone loss is hypothesized as the principal mechanism responsible for an estimated 35 to $50 \%$ reduction of hip fracture risk among users of thiazide diuretics [7-9]. These findings could be of significant clinical importance since thiazide diuretics are relatively inexpensive, well tolerated in low dosages by elderly patients, and could be used for treatment of men and women in whom use of estrogens is contraindicated [4]. However, several studies could not observe a risk reduction among users of thiazide diuretics [10-12]. If use of thiazide diuretics indeed slows bone loss, but on the other hand increases the risk for falling by other (e.g., postural hypotension) [13] or yet unknown mechanisms, the net effect

\footnotetext{
- Correspondence and reprint requests: Dr. R. M. C. Herings, Department of Pharmacoepidemiology and Pharmacotherapy, Utrecht Institute for Pharmaceutical Sciences, Utrecht University, P.O. Box 80.082, 3508 TB Utrecht, The Netherlands.

(Received for publication 2 November 1994).
}

on hip fracture risk may be disappointing. Because of the controversy regarding thiazide-associated hip fracture risk, prescribing and dosing differences, and the available assortment of thiazide-containing preparations, we performed a case-control study, with adjustment for a wide variety of medical risk factors for falling and osteoporosis.

\section{METHODS Setting}

The study used data from the PHARMO record linkage system, a database that contains the drug-dispensing records from community pharmacies and hospital discharge records of a defined population of 300,000 residents of 6 medium-sized cities in The Netherlands, of whom $52 \%$ were females and $30.6 \%$ were 45 years of age and older [14]. Because almost all patients designate a single pharmacy to fill their prescriptions from general practitioners or medical specialists, the dispensing histories are virtually complete [15]. The computerized drug-dispensing histories include data concerning the dispensed drug, the prescriber, the dispensing date, the amount dispensed, the prescribed dose regimens, and the estimated duration of use. For all residents, the drug-dispensing histories were linked to patient hospital discharge records using a probabilistic algorithm based on patient characteristics such as date of birth, gender, and general practitioner $[14,16]$. Validation of 9,822 linked records showed that both registers are linked with a sensitivity and specificity both exceeding $95 \%$, which is comparable to record linkage systems based on unique personal identifiers [17]. The hospital records were obtained from the Dutch Center for Health Care Information, a corporation that collates all hospital discharge records in The Netherlands into a standardized format. These records include detailed information concerning the primary and secondary diagnoses, procedures, and dates of admission and dis- 
charge [18]. All diagnoses are coded according to the International Classification of Disease, Ninth Revision-Clinical Modification (ICD-9. CM). All hospitals use ICD-9-CM E-codes to code for accidental injuries.

\section{Selection of Case and Control Patients}

Patients, 45 years of age and newly admitted for a femur fracture (ICD-9-CM primary diagnosis code of 820 or 821 ) between January 1 , 1986 through December 21, 1990, were identified from the automated hospital records. For each of these case patients, an age- (within 3 years), sex-, pharmacy-, and general practitioner-matched control was randomly selected from the automated drug-dispensing records. An index date, the date of femur fracture for case patients, and a corresponding date for control patients were assigned to each patient. Cases and controls had therefore exactly the same length of dispensing and hospital admission histories available prior to the index date. Control patients had to be alive at the time of hospitalization of a case patient. Given an estimated exposure prevalence of thiazides of $18 \%$, we estimated that approximately 300 patients were needed to detect a relative risk of $0.5(\alpha=0.05$ and power $=80 \%)$.

Cases and controls were excluded if they had less than 2 months of drug-dispensing history prior to the index date, had evidence of nursing home residence or hospital admission as of the index date, or had a preventive hip replacement. Of the eligible 386 cases, 357 were admitted for a fracture of the femoral neck and 29 for fractures of other or unspecified parts of the femur.

\section{Validation}

The primary medical records of 57 cases in 1 of the 6 cities were reviewed with respect to the type of the fracture (femur and nonfemur fractures) and whether surgical procedures were performed for reconstruction of the fracture. All 57 cases represented true femur fractures and surgical procedures for reconstruction of the fracture were recorded for 54 of these patients (93.1\%): 2 patients were mobilized with physiotherapy and 1 patient died 1 day after he had been admitted. Validation of the femur fractures in other cities was not performed because an analysis of the procedure codes recorded in the computerized hospital records of all 386 cases also showed that $93.8 \%$ of the cases underwent a procedure compatible with a reconstruction of the femur fracture. Therefore, less than $6.2 \%$ of all diagnoses of femur fractures may have been misclassified, which was also found by others [7].

\section{Use of Thiazide Diuretics}

Use of thiazide and other diuretics was ascertained from computerized records of prescriptions filled at the community pharmacies for the period of 1986 to 1990 . For each prescription of a diuretic, the duration of each treatment cycle was estimated from the number of dispensed tablets divided by the prescribed number of tablets per day. The total exposure period per patient was calculated by adding the duration of all treatment cycles prior to the index date, corrected for overlap of prescriptions. Current users were defined as persons whose index date was between the dispensing date of the thiazide and the estimated discontinuation date. Long-term users were defined as those who used thiazides for more than 1 year. Former users were those not currently exposed but who had been prescribed thiazides in the year before the index date. To study the effect of discontinuation of thiazides, former users were stratified into those who discontinued use within 2 months and those who discontinued prior to 2 months of the index date. We also calculated the prescribed daily dose of each patient as a fraction of the defined daily dose (DDD) [19]. The DDD of a thiazide diurctic also equals the standard recommended adult daily dose for treatment of hypertension in The Netherlands.

\section{Assessment of Potential Confounders}

Using information of the automated pharmacy database, we identified patients who currently used medications that have been associated with an increased risk for accidental injury (benzodiazepines, $\mathrm{H}_{1}$ antihistamines, antidepressants, antimigraine preparations, neuroleptics, and opioid analgesics), medication that may influence bone metabolism (glucocorticoids, aluminum-containing antacids, estrogens, vitamin $\mathrm{D}$, calcium, fluor preparations, or etridonates), and other drugs of which an increased risk for femur fracture has been reported in the literature (nonsteroidal antiinflammatory drugs, laxatives) [20-22].

Using information from the hospitalization records, we noted whether the case and control patients had a history of hypertension, organic hrain syndrome, anemia, glaucoma, severe rheumatological disease, neoplasms, cerebrovascular disease, peripheral vascular disease, cardiac disease (congestive heart failure, myocardial infarction, or cardiac arrhythmia), chronic obstructive pulmonary disease, asthma, diabetes, incontinence, seizure disorders, Parkinson's disease, and a history of hospitalization for other fractures [22-24]. In addition to noting the presence of ICD-9-CM codes we also identified drugs used to treat these diseases (Appendix) [25]. Total days spent in the hospital in the year previous to the index date was also assessed [26].

\section{Statistical Analysis}

Conditional logistic regression analyses were performed using EGRET [27] to estimate the crude and adjusted odds ratio and $95 \%$ confidence intervals for femur fracture associated with use of thiazides. Adjusted estimates of the odds ratio were controlled for the potential confounding cffects of a history of any hospitalization in the preceding year, d history of fractures, organic brain syndrome, mental illness, severe rheumatological disorders, cerehrovascular disease, peripheral arterial disease, anemia, seizure disorders, incontinence, a history of use of drugs used to treat osteoporosis (estrogen, vitamin $\mathrm{D}$, calcium, fluor, or etridonates), and current or former use of psychotropic drugs, furosemide, or corticosteroids. These factors were selected because either they caused a change in the crude matched odds ratio of at least $10 \%$ or because of a substantial association of thiazides with hospitalization for femur fractures (odds ratio, $>1.5$ or $<0.67$ ) in our data set $[10,28]$. Subgroup analyses were performed for males and females by applying the same final multivariate model used in the total sample. The effects of dose, duration, and discontinuation of thiazide use were also studied, using the same final multivariate models as used for the total population.

\section{RESULTS}

The cases and controls had a mean observation period of 2.3 years prior to the index date. Of the cases, $69.2 \%$ were older than 75 years of age and $11.9 \%$ were older than 90 years of age (Table 1). Approximately $75 \%$ of the cases were women. The health status of case patients was poorer than that of control patients, as measured by days of hospitalization in the year prior to the index date. Medical conditions found to be more prevalent among case patients than among control patients were anemia, severe rhcumatological disease, organic brain syndrome, cerebrovascular disease, peripheral arterial disease, 
TABLE 1. Baseline distribution of matching factors, medical factors, and exposures

\begin{tabular}{|c|c|c|}
\hline Characteristic & $\begin{array}{c}\text { Cases } \\
(n=386)\end{array}$ & $\begin{array}{c}\text { Controls } \\
(n=386)\end{array}$ \\
\hline Mean age (yr) & 78 & 78 \\
\hline Sex (males) & $25.1 \%$ & $25.1 \%$ \\
\hline \multicolumn{3}{|l|}{ Days hospitalized in previous year } \\
\hline 0 days & $77.5 \%$ & $88.1 \%$ \\
\hline $1-9$ days & $5.2 \%$ & $6.2 \%$ \\
\hline$>9$ days & $15.3 \%$ & $5.7 \%$ \\
\hline $\begin{array}{l}\text { One or more prescriptions as of the index } \\
\text { date }\end{array}$ & $77.0 \%$ & $79.4 \%$ \\
\hline \multicolumn{3}{|l|}{ Medical condition } \\
\hline Hypertension & $32.9 \%$ & $34.2 \%$ \\
\hline Cardiac disease & $24.9 \%$ & $24.6 \%$ \\
\hline Incontinence & $22.5 \%$ & $14.2 \%$ \\
\hline Anemia & $16.1 \%$ & $9.6 \%$ \\
\hline COPD and asthma & $14.8 \%$ & $12.4 \%$ \\
\hline Diabetes & $9.1 \%$ & $11.7 \%$ \\
\hline Glaucoma and cataract & $7.3 \%$ & $7.5 \%$ \\
\hline Mental disorders and dementia & $6.4 \%$ & $2.6 \%$ \\
\hline $\begin{array}{l}\text { Peripheral and cerebrovascular dis- } \\
\text { orders }\end{array}$ & $6.0 \%$ & $1.0 \%$ \\
\hline Parkinson disease & $4.9 \%$ & $3.6 \%$ \\
\hline $\begin{array}{l}\text { History of fracture (excluding hip } \\
\text { fracture) }\end{array}$ & $4.7 \%$ & $1.8 \%$ \\
\hline Epilepsy & $3.4 \%$ & $2.3 \%$ \\
\hline Severe rheumatological disease & $3.4 \%$ & $0.3 \%$ \\
\hline \multicolumn{3}{|l|}{ Current use of medications } \\
\hline Benzodiazepines & $30.0 \%$ & $23.3 \%$ \\
\hline Nonsteroidal antiinflammatory drugs & $12.4 \%$ & $8.5 \%$ \\
\hline Laxatives & $11.1 \%$ & $4.1 \%$ \\
\hline Furosemide & $11.1 \%$ & $9.1 \%$ \\
\hline $\mathrm{H}_{1}$-Antihistamines & $6.7 \%$ & $3.9 \%$ \\
\hline Neuroleptics & $3.1 \%$ & $1.8 \%$ \\
\hline Antidepressants & $2.8 \%$ & $1.8 \%$ \\
\hline \multicolumn{3}{|l|}{ Former use of medications } \\
\hline Furosemide & $15.6 \%$ & $8.8 \%$ \\
\hline Estrogen, calcium, fluor, or vitamin D & $12.4 \%$ & $8.8 \%$ \\
\hline Systemic glucocorticoids & $10.9 \%$ & $4.7 \%$ \\
\hline
\end{tabular}

and treatment of osteoporosis. A history of nonfemur fractures was also associated with an increased risk for femur fracture.

Case and control patients did not differ in the use of any one or more drugs at the index date. Benzodiazepines were the most commonly used drugs among cases and controls and were found to be more prevalent among case patients compared to control patients $(30.0$ and $23.3 \%$, respectively).

Twelve percent of the cases and $18 \%$ of controls were current users of thiazides as of the index date. Ninety-six patients $(12.6 \%)$ used a thiazide diuretic in combination with either triamterene or aniluride: epitizide and triamterene $(n=41)$, hydrochlorthiazide and triamterene $(n=26)$, hydrochlorthiazide and amiloride $(n=29)$. Monopreparations of thiazide diuretics used by the study group were chlortalidone alone $(n=13)$, hydrochlorthiazide alone $(n=4)$, chlorthiazide alone $(n=1)$, and cyclopenthiazide alone $(n=1)$. Other diuretics used by the study group were furosemide $(n=78)$ and spironolactone $(n=6)$.

The crude odds ratio for femur fracture associated with current use of thiazides was 0.6 (95\% confidence interval [CI] 0.4-0.9) (Table 2). The odds ratio for femur fracture among patients solely using thiazides was 0.4 (95\% CI, 0.3-0.8) whereas a higher risk was observed for patients using both thiazides and benzodiazepines (odds ratio [OR], $1.2 ; 95 \% \mathrm{CI}, 0.6-2.3)$. Controlling for potential confounders lowered the odds ratio only slightly from $0.6(95 \% \mathrm{CI}, 0.4-0.9)$ to $0.5(95 \%$ $\mathrm{CI}, 0.3-0.9)$. Although the protective effects was more prominent in males than in women, this difference was not statistically significant $(p=0.2)$. The largest confounding effect was observed for concomitant use of benzodiazepines: $53.2 \%$ of cases and $28.1 \%$ of controls using thiazides also used benzodiazepines concomitantly.

The majority of the cases and controls $(70.2 \%$ and $62.9 \%$, respectively) were currently using thiazide at doses equal to 0.5 times the standard dose. The odds ratio for femur fracture was lowest for those using one or more defined daily doses (OR, 0.4; $95 \% \mathrm{CI}, 0.2-0.8)$. A lower risk for femur fracture was observed among patients who used thiazides for longer than 1 year (OR, $0.4 \% ; 95 \% \mathrm{CI}, 0.2-0.8$ ). The greatest risk reduction was observed among patients who used one or more defined daily doses of thiazides for longer than 1 year $(\mathrm{OR}, 0.3$; 95\% CI, 0.1-0.9).

The risk of femur fracture was also examined among patients who formerly used thiazides. Forty-eight case patients and 51 control patients were identified as former users of thiazides. Among patients who discontinued use of thiazide diuretics longer than 2 months before the index date, we observed no risk reduction for femur fracture (OR, 0.8 ; 95\% CI, 0.4-1.4) whereas patients who discontinued use of thiazide diuretics within 2 months of the index date had an odds ratio of 0.4 (95\% CI, 0.2-0.9).

TABLE 2. Risk of femur fracture among users of thiazide diuretics

\begin{tabular}{|c|c|c|}
\hline Characteristic & $\begin{array}{c}\text { Crude odds } \\
\text { ratio } \\
(95 \% \mathrm{CI})\end{array}$ & $\begin{array}{c}\text { Adjusted odds } \\
\text { ratio } \\
(95 \% \mathrm{CI})\end{array}$ \\
\hline \multicolumn{3}{|l|}{ Gender } \\
\hline Male & $0.3(0.1-0.9)$ & $0.2(0.1-0.7)$ \\
\hline Female & $0.7(0.5-1.2)$ & $0.6(0.4-1.0)$ \\
\hline \multicolumn{3}{|l|}{ Type } \\
\hline Pure thiazide & $0.4(0.2-1.0)$ & $0.3(0.1-0.9)$ \\
\hline Combination & $0.7(0.4-1.1)$ & $0.6(0.4-1.0)$ \\
\hline \multicolumn{3}{|l|}{ Dosage } \\
\hline $0.1-0.75$ DDD eq. & $0.7(0.4-1.1)$ & $0.6(0.4-1.1)$ \\
\hline$>0.75$ DDD eq. & $0.5(0.2-0.9)$ & $0.4(0.2-0.8)$ \\
\hline \multicolumn{3}{|l|}{ Duration of use } \\
\hline$<1 \mathrm{yr}$ & $0.8(0.5-1.5)$ & $0.7(0.2-1.3)$ \\
\hline$\geq 1 \mathrm{yr}$ & $0.5(0.3-0.8)$ & $0.4(0.2-0.8)$ \\
\hline \multicolumn{3}{|l|}{ Duration by dosage } \\
\hline$<1$ yr, $0.1-0.75$ DDD eq. & $0.9(0.4-1.7)$ & $0.9(0.4-1.7)$ \\
\hline$<1 \mathrm{yr},>0.75$ DDD eq. & $0.8(0.3-1.2)$ & $0.4(0.1-1.3)$ \\
\hline$\geq 1 \mathrm{yr}, 0.1-0.75 \mathrm{DDD}$ eq. & $0.6(0.3-1.1)$ & $0.5(0.2-1.1)$ \\
\hline$\geq 1 \mathrm{yr},>0.75$ DDD eq. & $0.3(0.1-0.9)$ & $0.3(0.1-0.9)$ \\
\hline \multicolumn{3}{|l|}{$\begin{array}{l}\text { Discontinuation beforc index } \\
\text { date }\end{array}$} \\
\hline Within 2 months & $0.6(0.3-1.3)$ & $0.4(0.2-0.9)$ \\
\hline Before 2 months & $1.1(0.6-1.8)$ & $0.8(0.4-1.4)$ \\
\hline Overall & $0.6(0.4-0.9)$ & $0.5(0.3-0.9)$ \\
\hline
\end{tabular}

${ }^{a}$ Adjusted for days hospitalized before the index date; history of hospitalization for nonhip fractures; presence of severe rheumatological disease, anemia, organic brain syndrome, cerebrovascular disease, peripheral arterial disease, incontinence, and osteoporosis; and current use of benzodiazepines, antidepressants, $\mathrm{H}_{1}$-antihistamines, neuroleptics, furosemide (former and current), and systemic glucocorticoids.

Abbreviation: DDD, Defined daily dose. 


\section{DISCUSSION}

Our findings provide evidence that the use of thiazide diuretics is associated with a decreased risk for femur fracture [7-9]. This risk reduction was dose and duration dependent in that the protective effect was greatest among those who used thiazides longer than 1 year at doses comparable to $50 \mathrm{mg}$ of hydrochlorothiazide or higher. Among patients who discontinued use of thiazides more than 2 months before the index date, no risk reduction could be observed, suggesting that any risk reduction is short-lived. The latter finding is consistent with observations made by Transbol et al., who found that bone density returned to baseline levels after 1 month when use of thiazide diuretics was discontinued [5]. Because we did not have data on hone mineral density and bone mineral turnover is slow, another yet unknown mechanism could be responsible for the loss of risk reduction after discontinuation of thiazides and interpretation of these results should be done carefully.

The risk reduction was most evident among users of pure thiazide diuretics compared to patients using thiazide-containing combination pills. This difference is probably explained by the $50 \%$ lower content of thiazides in combination pills [9]. Our findings support the postulated mechanism that thiazides cause an increase in renal calcium reabsorption, thereby preventing bone loss and reducing the risk of femur fractures [4].

Selection bias of controls is unlikely to explain the observed decreased relative risk. To assure that controls were alive and eligible for thiazide use and hospitalization for femur fracture, controls had to fill any prescription before and after the index date. Healthy patients who never filled a prescription were thereby excluded, potentially resulting in an overestimation of the prevalence of use of thiazide diuretics and thus an overestimation of the observed risk reduction. However, using age- and gender-specific prevalence estimates of the total PHARMO population, we estimated the number of control patients who used thiazides as 67 as against 70 observed.

Our study differed in several aspects from studies addressing thiazideassociated femur fracture risk. First, proximal femur neck fractures are typical of those suffering from type II osteoporosis [3]. Excluding the unspecified femur fractures (ICD-9-CM code 821) did not, however, influence the risk estimates. Second, the most prescribed daily dose of thiazide diuretics in our study (66\%) was comparable to $25 \mathrm{mg}$ of hydrochlorthiazide, which was much lower than in studies performed in the United States, where doses equal to $50 \mathrm{mg}$ of hydrochlorthiazide are most frequently prescribed [9-11]. High doses of thiazide diuretics might increase the risk for volume depletion and thus orthostatic or postural hypotension, resulting in an increased risk for femur fractures by falling [4]. If such a phenomenon exists, thiazide use might follow a "J-shaped" dose-dependent risk relationship for femur fractures: low doses are not associated with either mechanism and do not result in risk reduction or increase for femur fractures, whereas with increasing dose the risk for falling caused by postural or orthostatic hypotension then could supersede the protection against femur fractures as a result of slowing bone loss. This effect could be more pronounced if combination pills of thiazide diuretics and reserpine or methyldopa, the two latter drugs associated with an increased risk for orthostatic hypotension, are frequently used. These combination pills are not prescribed in The Netherlands but are quite commonly used by subjects studied by Felson et al. [9]. However, more studies specifically designed to study this hypothetical dose relationship are needed.

Although we found evidence that particular prevailing diseases (e.g., epilepsy, anemia, peripheral and cerbrovascular diseases) and use of psychotropic drugs (e.g., benzodiazepines, antidepressants, and neuroleptics) were more prevalent among patients with femur fractures, controlling for these potential risk factors had only a minor effect on the risk of hospitalization for femur fractures associated with the use of thiazide diuretics (Table 2). However, some of the morbidity markers used (e.g., dementia) might not have been specific or sensitive enough to control for confounding. Furthermore, we could not control for the potential confounding effects of body weight, use of alcohol, or functional disabilities. These data were not available or not consistently recorded in the primary medical records and could not be obtained for the control patients. However, although others did not control for these potential confounding risk factors and found an association between these and the risk of falling, their presence did not explain the increased risk for falling among users of thiazide diuretics $[9,10,29]$. We therefore have no reason to believe that the observed decreased risk among users of thiazide diuretics is explained by differences in body weight, functional disabilities, use of alcohol, or lack of controlling for prevailing diseases using morbidity markers.

Clinical trials are needed to demonstrate the hypothesized calciummediated mechanism responsible for slowing bone loss and reduction of femur fracture risk among users of thiazides [30]. However, even if large randomized clinical trials demonstrate such a mechanism, we doubt whether use of thiazide diuretics will become a first line therapy for the prevention of femur or hip fractures. Our data suggest that long-term use of high doses of thiazides is required to achieve a substantial protection against femur fractures. Moreover, discontinuation of thiazide use might result in a rapid loss of this protection. Discontinuation can probably not be avoided because, especially among elderly with impaired renal function, thiazides lack efficacy in lowering blood pressure or treatment of edemas. Furthermore, use of high doses of thiazides in the elderly could increase the risk for falling and partially undo the risk reduction resulting from slowing bone loss, whereas the frequency of serious adverse effects, including sudden death, cannot be ignored [31].

\section{References}

1. Anonymous. Jaarboek Ziekenhuizen: Kliniek en Dagverpleging. SIG/Informatiecentrum voor de Gezondheidszorg, Utrecht, The Netherlands, 1991.

2. Meer van der-Dappendijk S. Cost-Benefit Analysis of a National Screening Programme of the Prevention of Osteoporosis. An Overall Model for the Dutch Situation. Haarlem Business School (MBA Project Series), Haarlem, The Netherlands, 1994.

3. Cummings SR, Kelsey JL, Nevitt MC, O'Dowd KJ. Epidemiology of osteoporosis and osteoporotic fractures. Epidemiol Rev 1985; 7: 178-208.

4. Thapa PB, Ray WA. Can thiazide diuretics be recommended routinely to reduce hip fracture risk? Drugs Aging 1993; 3(2): 99-105.

5. Transbol I, Christensen MS, Jensen GF, Christiansen C, McNair P. Thiazide for the postponement of postmenopausal bone loss. Metabolism 1982; 31(4): 383-386.

6. Wasnich RD, Davies J, Ross P, Vogel J. Effect of thiazide on rates on bone mineral loss: A longitudinal study. Br Med J 1990; 301: 1303-1305.

7. Ray WA, Downey W, Griffin MR, Melton JL III. Long-term use of thiazide and the risk of hip-fracture. Lancet 1989; 1: 687-690.

8. LaCroiz AZ, Wienpahl J, White LR, et al. Thiazide diuretic agents and the incidence of hip fractures. N Engl J Med 1990; 322(5): 286-290.

9. Felson DT, Sloutkis D, Anderson JJ, Anthony JM, Kiel DP. Thiazide diuretics and the risk of hip fracture. Result from the Framingham Study. JAMA 1991; 265(3): 370-373.

10. Heidrich FE, Stergachis A, Gross KM. Diuretic drug use and the risk for hip fracture. Ann Intern Med 1991; 115(1): 1-6.

11. Cauley JA, Cummings SR, Seeley DG, et al. Effects of thiazide diuretic therapy on bone mass, fractures and falls. Ann Intern Med 1993; 118: 666-673. 
12. Cumming RG, Klineberg RJ. Psychotropics, thiazide diuretics and hip fractures in the elderly. Med J Austr 1993; 158: 414-417.

13. Myers MG, Kearns PM, Kennedy DS, Fisher RH. Postural hypotension and diuretic therapy in the elderly. Can Med Assoc J 1978; 119: 581-585.

14. Herings RMC. PHARMO: A Record Linkage System for Postmarking Surveillance of Prescription Drugs in The Netherlands. Ph.D. dissertation. Department of Pharmacoepidemiology, Utrecht University, Utrecht, The Netherlands, 1993, p. 207.

15. Leufkens HGM, Urquhart J. Automated record linkage and other approaches to pharmacoepidemiology in The Netherlands. In: Pharmacoepidemiology, 2nd Ed. John Wiley \& Sons, Chichester, 1994, pp. 231-244.

16. Howe GR, Lindsay J. A generalized iterative record linkage computer system for use in medical follow-up studies. Comput Biomed Res 1981; 14: $327-340$.

17. Gill LE, Baldwin JA. Methods and technology of record linkage: Some practical considerations. In: Textbook of Medical Record Linkage (Baldwin JA, Arheson ED, Graham WJ, eds.). Oxford University Press, New York, 1987; pp. 39-55.

18. Hoogendoorn D. Stichting informatiecentrum voor de gezondheidszorg (SIG). In: Epidemiologie en Gezondhcidsbeleid. (Maas van der PJ, Hofman A, Dekker E, eds.) Samson Stafleu, Alphen aan den Rijn, pp. 31-41.

19. Anonymous. Anatomical Therapeutic Classification (ATC) Index: Including Defined Daily Doses (DDD) for Plain Substances. World Health Organization, Oslo, 1992.

20. Ray WA, Griffin MR, Downey W. Benzodiazepines of long and short elimination half-life and the risk of hip fracture. JAMA 1989; 262(23): 3303-3307.

21. Ray WA, Griffin MR, Malcolm E. Cyclic antidepressants and the risk of hip fracture. Arch Intern Med 1991; 151: 754-756.
22. Granek E, Baker SP, Abbey $\mathrm{H}$, et al. Medications and diagnoses in relation to falls in a long-term care facility. J Am Geriatr Soc 1987; 35: 503-511.

23. Paulson GW, Schafer $K$, Hallum B. Avoiding mental changes and falls in older Parkinson's patients. Geriatrics 1986; 41(8): 59-67.

24. Ryynanen O-P, Kivela S-L, Honkanen R, Laippala P, Saano V. Medications and chronic diseases as risk factors for falling injuries in the elderly. Scand J Soc Med 1993; 12(4): 264-271.

25. Deyo RA, Cherkin DC, Ciol MA. Adapting a clinical comorbidity index for use with $1 \mathrm{CD} 9 \mathrm{CM}$ administrative databases. J Clin Epidemiol 1992; 45(6): 613-619.

26. Tinetti ME, Speechley MS, Ginter SF. Risk factors for falls among elderly persons living in the community. N Engl J Med 1988; 319(26): 17011707.

27. SERC. EGRET. Statistic and Epidemiology Research Corporation (SERC), Seattle, Washington.

28. Greenland S. Modeling and variable selection in epidemiologic analysis. Am J Public Health 1989; 79(3): 340-348.

29. Nelson DE, Sattin RW, Langlois JA, DeVito CA, Stevens JA. Alcohol as a risk factor for fall injury events among elderly persons living in the community. J Am Geriatr Soc 1992; 40: 658-661.

30. Ray WA. Thiazide diuretics and osteoporosis: Time for a clinical trial (letter). Ann Intern Med 1991; 115: 64-65.

31. Siscovick DS, Raghunathan TE, Psaty BM, Koepsell TD, Wicklund KG, Lin X, Cobb L, Rautuharju PM, Copass MK, Wagner EH. Diuretic therapy for hypertension and the risk of primary cardiac arrest. N Engl J Med 1994; 330: 1852-1857.

\section{APPENDIX}

Morbidity Markers and Drugs to Profile Case and Control Patients

\begin{tabular}{ll}
\hline Morbidity marker & \multicolumn{1}{c}{ ICD-9-CM codes $^{a} /$ Specific drug classes $^{b}$} \\
\hline Severe theumatological disorders & $710.0,710.1,710.4,714.1,714.8 /$ specific antirheumatic preparations \\
Mental disorders and dementia & $290.0-290.9,291-319 /$ dihydroergocrine \\
Peripheral/cerebrovascular disorders & $443.9,441.0,441.9,785.4,430-438$ \\
Epilepsy & $345-345.9 /$ antiepileptics \\
History of fractures & $800-850$ (excluding hip fractures $820-821)$ \\
Anemia & $280-289 /$ antianemic preparations \\
Parkinson's disease & $332.0-332.9 /$ anti-Parkinsonian drugs \\
Incontinence & Oxybutynine, flavoxate, or incontinence pads \\
Congestive heart failure or arrhythmia & $426-427.9,428-428.9 /$ cardiac therapeutics \\
Hypertension ${ }^{c}$ & Thiazide diuretics, beta-blocking agents, angiotensine converting enzyme inhibitors, or other anti- \\
& hypertensive use longer than 180 days \\
Glaucoma and cataract & $365.0-365.9,360.0-379.9 /$ antiglaucoma eyedrops \\
Cancer & $140.0-171.9,174-195.8,200.0-208.9 /$ antineoplastic drugs \\
COPD and asthma & Antiasthmatics \\
Diabetes mellitus & $725-729,250-250.9 /$ antidiabetics
\end{tabular}

\footnotetext{
ICD-9-CM: International Classification of Diseases, Ninth Revision-Clinical Modification.

${ }^{b}$ Use of drugs or admissions for disease in the year prior to the hip fracture.

'In the logistic model these drug groups are included separately.

Abbreviation: COPD, Chronic obstructive pulmonary disease.
} 